\title{
Novel Competitive Voltammetric Aptasensor Based on Electrospun Carbon Nanofibers-Gold Nanoparticles Modified Graphite Electrode for Salmonella enterica serovar Detection
}

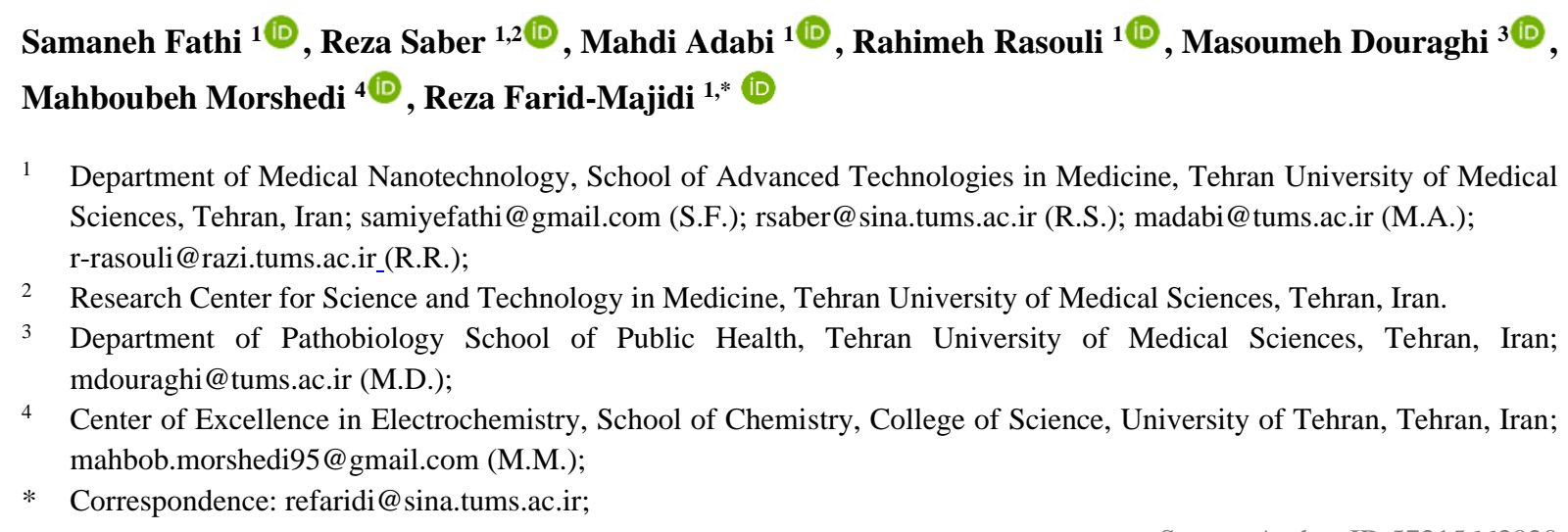

Received: 2.07.2020; Revised: 3.08.2020; Accepted: 5.08.2020; Published: 8.08.2020

\begin{abstract}
Salmonella enterica is considered one of the most common bacterial agent causes of acute gastroenteritis and foodborne illness in humans worldwide. Antibiotic-resistant is considered as a major problem in Salmonella enterica Serovar. This study introduces a new simple and sensitive aptasensor based on chitosan (Chi)-electrospun carbon nanofibers (CNF) /gold nanoparticles (GNPs) decorated pencil graphite electrode (GE) as a novel platform for electrochemical detection of Salmonella enterica Serovar. A Salmonella-specific recognition aptamer ssDNA sequence was used in the development of this voltammetric biosensor. Electrochemical behaviors of electrodes; unmodified GE, CNF-Chi/GE, GNPs/CNF-Chi/GE, GNPs/CNF-Chi/GEs linked with the aptamer were studied by cyclic voltammetry (CV) and electrochemical impedance spectroscopy (EIS). After the optimization of experimental conditions (e.g., CNF concentration, $\mathrm{pH}$, and incubation time), electrochemical detection of Salmonella was performed via differential pulse voltammetry (DPV) in methylene blue solution. The designed aptasensor exhibited a linear range of 10 to $10^{5}(\mathrm{CFU} / \mathrm{mL})$ with the limit of detection (LOD) 1.223 $(\mathrm{Cfu} / \mathrm{mL})$ for Salmonella. This aptasensor displayed excellent selectivity and remarkable sensitivity in terms of the detection of Salmonella enterica even in the real samples as compared to the polymerase chain reaction (PCR) technique. The constructed aptasensor is a highly sensitive sensor for the detection of Salmonella enterica and also can be tailored for various other targets.
\end{abstract}

Keywords: Aptasensor; carbon nanofiber; gold nanoparticle; Salmonella enterica serovar.

(C) 2020 by the authors. This article is an open-access article distributed under the terms and conditions of the Creative Commons Attribution (CC BY) license (https://creativecommons.org/licenses/by/4.0/).

\section{Introduction}

Salmonella enterica, a major factor in gastrointestinal infections, is considered as one of the most frequently available foodborne pathogenic bacteria in contaminated foods such as meat, eggs, milk, and other animal products that cause human illness. According to the Center for Disease Control and Prevention (CDC) report, in the United States, about two percent of 
foodborne illness is due to contamination of Salmonella enterica, which results in about 19000 hospitalizations and 380 death [1].

Antibiotic-resistant is considered as a major problem in Salmonella enterica Serovar $[2,3]$. Early detection has gained more attention as the first critical step in the prevention of diseases caused by this type of foodborne pathogens.

Traditional methods including the combination of pre-enrichment phases, bacterial culture methods, serological validation of the specified colonies [4], enzyme-linked immunosorbent assay (ELISA) [5] and polymerase chain reaction (PCR) [6] as reliable, sensitive and selective techniques for the detection and identification of these bacteria have been applied [7]. Although these approaches are time-consuming and labor-intensive [8]. Therefore, to overcome these drawbacks, a novel procedure is needed for the detection of Salmonella enterica. Electrochemical biosensors have widely attracted great attention due to some unique properties such as reliability, high sensitivity and selectivity, low cost, easy and fast operation, and often portability [9-13].

Biosensors that employ a nucleic acid aptamer (single-stranded DNA or RNA molecules) as a specific recognition segment called an aptasensor. Several features of aptamers make them ideal for bio-diagnostic applications, such as small size, ease of handling and labeling, no immunogenicity, low price of synthesis, and high affinity to a target site.

Of the electrochemical biosensors, aptasensors as a quick, sensitive and cost-effective platform have received special attention for the detection of protein [14], drugs [15], virus [16], cancerous cells [17] and antibiotics [18]. In the current study, the aptamer sequence was evaluated by Joshi R. et al. and Ma et al. In this study, the DNA aptamers of S. enterica serovar were chosen. Because of the high specific recognition property of the aptamer, Salmonella enterica could be diagnosed $[19,20]$.

Nowadays, unique and intrinsic features of nanomaterials provide great potential in the field of biomedical and healthcare applications especially in the development of a new generation of sensors [21,22] for instance, the conducting nanomaterials such as GNPs [23], and CNF [24], by increasing the conductivity and accelerating the electron can enhance the sensitivity and detection limits for analytics.

Also, many other nanomaterials such as carbon nanotubes (CNT) [25], graphene [26], graphite [27], carbon dots [28], gold nanorods [29], gold nanowires [30], and other inorganic wires [31], platinum [32] and silver nanoparticles [33] have been used in the development of electrochemical biosensors.

Many studies have demonstrated that gold nanoparticles (GNPs) due to their unique features, for instance, bio-compatibility, high conductivity, and electrocatalytic ability [34], as well as their simple functionalization through thiolation, to be promising candidates for their application in enhancing of electron transfer in electrochemical biosensors [35].

Electrospinning is a versatile technique to prepare nanofibers in a wide range of diameters [36-44]. Among carbon-based materials (graphene, carbon nanotubes, carbon nanofillers, activated carbons, etc.), electrospun CNFs as one-dimensional material with large surface area to volume ratio and highly- interconnected porous structure, can be used to modify the surface of electrodes and apply for immobilization/adsorption of biomolecules and enhance the electron conductive pathway [45].

The advantage of CNFs over carbon nanotubes can be their high purity due to free catalyst synthesis during stabilization and carbonization, which facilitate electron transfer [46]. 
Chitosan (Chi) is composed of the N-deacetylate derivative of chitin. To date, Chi has been used in electrochemical biosensors because of properties such as biocompatibility, membrane-forming property, ion-transport, and ion-exchange ability. Another valuable feature of Chi is its chemical structure that includes the excess of hydroxyl $(-\mathrm{OH})$ and amine $\left(-\mathrm{NH}_{2}\right)$ groups along its chains that can be utilized to chemical modification and tune materials' properties. An additional advantage of Chi is its adhesive film-forming property in many medical and technical applications [47,48].

Methylene blue (MB) was employed as an external redox indicator of a hybridization event. It is an organic dye that has been employed as an electron transfer mediator for the development of electrochemical biosensors [49]. Since its formal potential $\left(\mathrm{E}^{\mathrm{o}^{\prime}}\right)$ is between -0.10 to $-0.40 \mathrm{~V}$ at the $\mathrm{pH}$ range of $4-11$, which is near to the redox potentials of many biomolecules, therefore, it had been studied in many studies [50,51].

Here we report a sensitive and simple aptasensor for the detection of Salmonella enterica hybridization. Studies have exhibited that MB can interact with ssDNA and dsDNA differently; the voltammetric reduction signals of MB indicate hybridization [50,52].

The engineered electrode, GNPs/CNF-Chi/GEs linked with the aptamer, was characterized in terms of the electrochemical conductivity, its sensitivity and specificity as well as were compared with the PCR method.

\section{Materials and Methods}

Polyacrylonitrile (PAN, MW $150000 \mathrm{~g} / \mathrm{mol}$ ) was received from Polydactyl Company (Tehran, Iran). Chitosan (Chi, MW $100 \mathrm{KDa}$ ), N, N-dimethylformamide (DMF), potassium ferricyanide $\left(\mathrm{K}_{3}\left[\mathrm{Fe}(\mathrm{CN})_{6}\right]^{3-/ 4-}\right)$, acetic acid, Tween, tryptone, agar, and yeast extract were obtained from Merck (Darmstadt, Germany).

Potassium chloride $(\mathrm{KCl})$, chloroauric acid $\left(\mathrm{HAuCl}_{4}\right)$, sodium chloride $(\mathrm{NaCl})$, sodium dihydrogen phosphate $\left(\mathrm{NaH}_{2} \mathrm{PO}_{4}\right)$, methylene blue $(\mathrm{MB})$, disodium hydrogen phosphate $\left(\mathrm{Na}_{2} \mathrm{HPO}_{4}\right)$ were purchased from Sigma-Aldrich (St. Louis, USA).

The thiolated aptamer was synthesized by the Faza Biotech Company (Tehran, Iran). The following aptamer nucleotide sequence was used [20]:

\section{5'-HS-TATGGCGGCGTCACCCGACGGGGACTTGACATTATGACAG-3`}

The bacterial strain was purchased from the Pasteur Institute (Tehran, Iran).

\subsection{Instrumentation.}

All electrochemical experiments (cyclic voltammetry (CV) and electrochemical impedance spectroscopy (EIS)) were done by the Autolab potentiostat/galvanostat system (Eco Chemie, Utrecht, Netherlands) measured with NOVA 1.8 software.

The working, auxiliary, and reference electrodes were pencil graphite (GE), platinum rod, and $\mathrm{Ag} / \mathrm{AgCl}$ electrodes, respectively.

The electrode surface morphology and nanofiber diameter were determined by the scanning electron microscopy (SEM) (Philips XL-30, Eindhoven, The Netherlands), operating with an accelerating voltage of $20 \mathrm{kV}$.

\subsection{Synthesis of CNFs.}

The fabrication of CNFs was performed according to our previous works (Mirzaei et al., 2015). Briefly, after dissolving the PAN polymer in DMF solution at $50{ }^{\circ} \mathrm{C}$ to yield an 8 
wt.\% solution, the solution was electrospun at the feeding rate of the syringe pump was 1.00 $\mathrm{mL} / \mathrm{h}$, high-voltage $(20 \mathrm{kV})$. Drum rotation speed was $250 \mathrm{rpm}$, and the distance between the nozzle and collector was set to $15 \mathrm{~cm}$. CNFs were then formed by stabilization and carbonization electrospun PAN nanofibers. The stabilization of PAN nanofibers was performed in an oxygen atmosphere at $290{ }^{\circ} \mathrm{C}$ for $4 \mathrm{~h}$ with heating rate $1.5{ }^{\circ} \mathrm{C}$ min- 1 , and to carbonization; the stabilized nanofibers was placed at $1000^{\circ} \mathrm{C}$ for $1 \mathrm{~h}$ in a nitrogen $(99.9999 \%)$ atmosphere with a heating rate of $4^{\circ} \mathrm{C}$ min-1 in a furnace, respectively.

\subsection{Preparation of the aptasensor.}

Pencil graphite (diameter of $2 \mathrm{~mm}$ ) as a working electrode was polished on $\mathrm{SiC}$ paper, followed by washing with DW and then dried at RT.

$\mathrm{CNF} /$ chi was decorated on the surface of GE, by the drop-casting method. Briefly, 0.07 gr CNFs were dispersed in $1 \mathrm{~mL}$ DMF and ultrasonicated for $20 \mathrm{~min}$. Chi solution $(1 \% \mathrm{w} / \mathrm{v})$ was then dissolved in acetic acid (1\% v/v) and stirred until the clear solution appeared. Then $200 \mu \mathrm{L}$ of Chi solution was added to the CNF solution and sonicated for 5 min to obtain a homogeneous mixture. The mixture was then dropped onto the GE electrode and dried at RT.

The GNPs were electrochemically deposited on the surface of CNF-Chi modified GE. For this aim, CNF-Chi modified GE was immersed in chloroauric acid solution (1 mM). $5 \mu \mathrm{L}$ of the aptamer solution $(10 \mu \mathrm{M})$ was added on the surface of the GNPs/CNF-Chi modified GE and incubated at $4{ }^{\circ} \mathrm{C}$ overnight, then washed with DW. Afterward, the aptamer/GNPs/CNFChi modified GE was immersed into MB (20 mM) for $15 \mathrm{~min}$ and again washed with DW for three times. Each modification step was verified by $\mathrm{CV}$ technology in the range of +0.2 to -1.0 $\mathrm{V}$ at a scan rate of $50 \mathrm{mV} \mathrm{s}^{-1}$ for 30 cycles. Scheme 1 shows the electrode preparation steps.

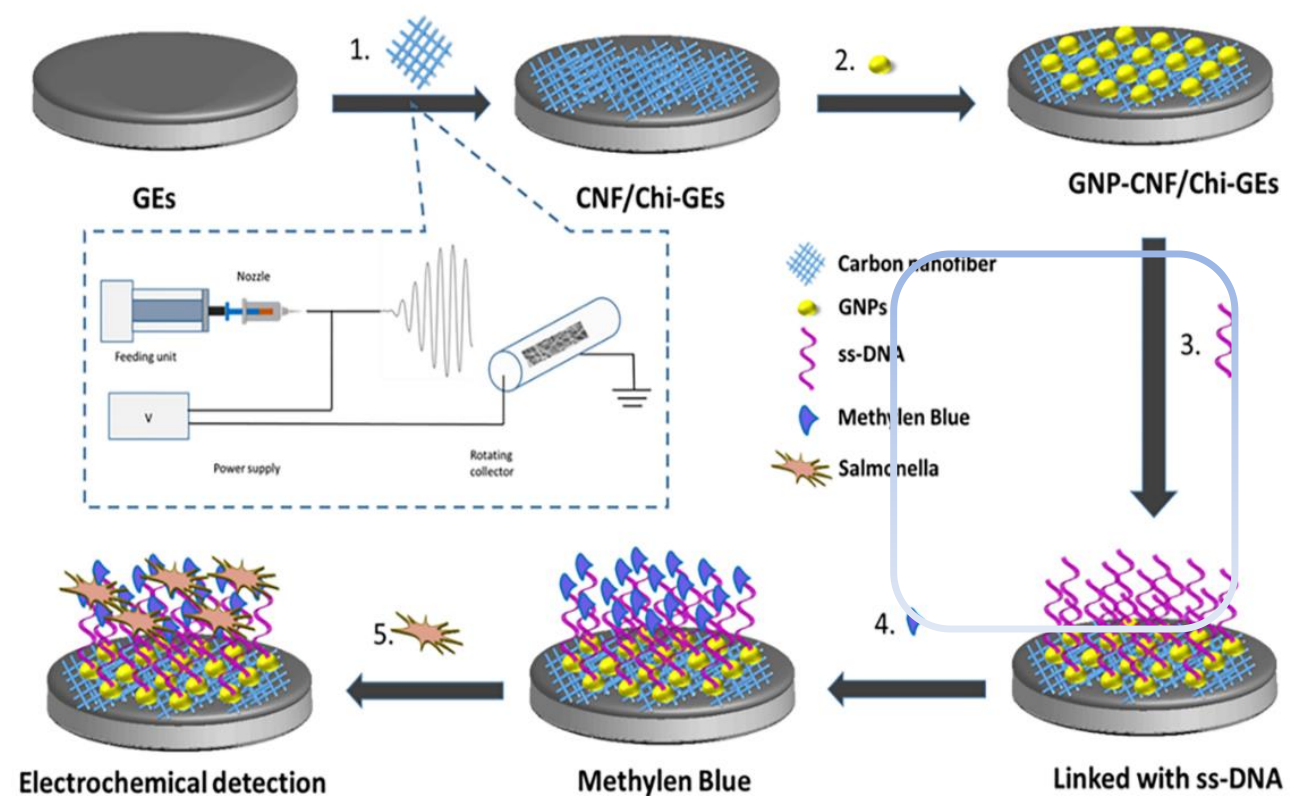

Scheme 1. Schematic illustration of the aptasensor fabrication steps. The surface of the GE was modified with aptamer-gold nanoparticle/ carbon nanofiber- chitosan (Apt-GNPs/CNF-Chi//GE). DPV was employed for the electrochemical detection of Salmonella enterica.

\subsection{Preparation of bacterial solution.}

Salmonella enterica was grown in the LB broth at $37^{\circ} \mathrm{C}$ for $12 \mathrm{~h}$. The enriched bacteria were centrifuged at $7000 \mathrm{rpm}$ for $15 \mathrm{~min}$ at RT, the supernatant was discarded, and the bacterial 
pellet was resuspended with PBS (0.1M, pH 7.4), then the optical density (OD) was measured at $625 \mathrm{~nm}$. The bacteria were diluted to reach OD value to 0.12 , and it was employed as the original sample of Salmonella enterica. Serial dilution of bacteria in seven concentrations from from $10^{-1}$ to $10^{-6}$ in PBS $(0.1 \mathrm{M}, \mathrm{pH} 7.4)$ was prepared, and then $100 \mu \mathrm{L}$ of each dilution was cultivated on the LB agar plate at $37{ }^{\circ} \mathrm{C}$ for $12 \mathrm{~h}$. Afterward, the colonies were counted to determine the salmonella enterica sample $(\mathrm{CFU} / \mathrm{mL})(\mathrm{CFU}=$ colony forming units) using the following formula(1) [20].

$$
\mathrm{N}=\sum C /(n 1+n 2) d
$$

\subsection{Electrochemical detection of bacteria.}

The modified GE was incubated with the prepared dilutions of the Salmonella enterica sample at RT to reach full interaction between bacterial and thiolated aptamer on the surface of an electrode, and then the electrode was washed with DW to remove the non-specific binding of bacteria. Finally, to electrochemical detection of bacteria, the electrode was immersed in the PBS (0.1M, pH 7.4) for $40 \mathrm{~min}$ at $37{ }^{\circ} \mathrm{C}$ and subsequently, DPV was measured.

The selectivity of the new aptasensor was investigated via different bacteria other than Salmonella enterica including, Escherichia coli, Pseudomonas aeruginosa, and Staphylococcus aureus as control bacteria. A $10^{3} \mathrm{CFU} / \mathrm{mL}$ of each bacterium was selected for DPV measurement, according to the same method, as described above.

2.6. $P C R$.

DNA Technology kit (DNA Technology, Dusseldorf, Germany) was used to extract genomic DNA from the serial dilution of Salmonella enterica following the manufacturer's instructions, and extracted DNA was used for PCR analysis [53]. Briefly, amplification reactions were done in a $20 \mu \mathrm{L}$ reaction volume, including $1 \mathrm{X}$ PCR buffer, forward and reverse primer $(0.2 \mathrm{mM})$, DNA Taq polymerase $(0.5 \mathrm{U}), \mathrm{MgCl}_{2}(1.5 \mathrm{mM})$, and DNA sample $(2 \mu \mathrm{L})$. The sequence of primers and PCR protocol is mentioned in Table 1.

Table 1. Primer sequences and PCR protocols were utilized to detect Salmonella enterica [54].

\begin{tabular}{|c|c|c|c|c|c|}
\hline Primer & $\begin{array}{l}\text { Primer } \\
\text { Length }\end{array}$ & Primer Sequence (5'-3') & PCR Protocol & & \\
\hline \multirow[t]{2}{*}{ ST11 } & \multirow[t]{2}{*}{24} & \multirow[t]{2}{*}{ GCCAACCATTGCTAAATTGGCGCA } & Initial Denaturation & $95^{\circ} \mathrm{C}$ & $5 \mathrm{~min}$ \\
\hline & & & 35 Cycles & $\begin{array}{l}94^{\circ} \mathrm{C} \\
56^{\circ} \mathrm{C} \\
72^{\circ} \mathrm{C}\end{array}$ & $\begin{array}{l}30 \mathrm{~s} \\
90 \mathrm{~s} \\
30 \mathrm{~s}\end{array}$ \\
\hline ST14 & 25 & GGTAGAAATTCCCAGCGGGTACTGG & Final Extension & $72^{\circ} \mathrm{C}$ & $\begin{array}{l}10 \\
\min \end{array}$ \\
\hline
\end{tabular}

\section{Results and Discussion}

\subsection{Characterization of the aptasensor.}

Figure $1 \mathrm{a}$ and $\mathrm{b}$ show the SEM images of the GNP-CNF/Chi-GEs and CNF/Chi-GEs. Due to the adhesive film-forming property of Chi, it was used to the attachment of CNF on the surface of GEs. There is an electrostatic attraction between CNF and Chi, so Chi was used to adhesion of CNF.

The GNPs were electrochemically deposited on the surface of CNF-Chi modified GE. GNPs as a biocompatible and highly conductive material, which can be employed for 
conjugating to thiol groups of the aptamer. As can be seen in Figure 1 the morphology of GNPsCNF/Chi modified GE is porous, and the diameter of CNFs and GNP is around $90 \pm 10 \mathrm{~nm}$ and $200 \pm 5 \mathrm{~nm}$, respectively.

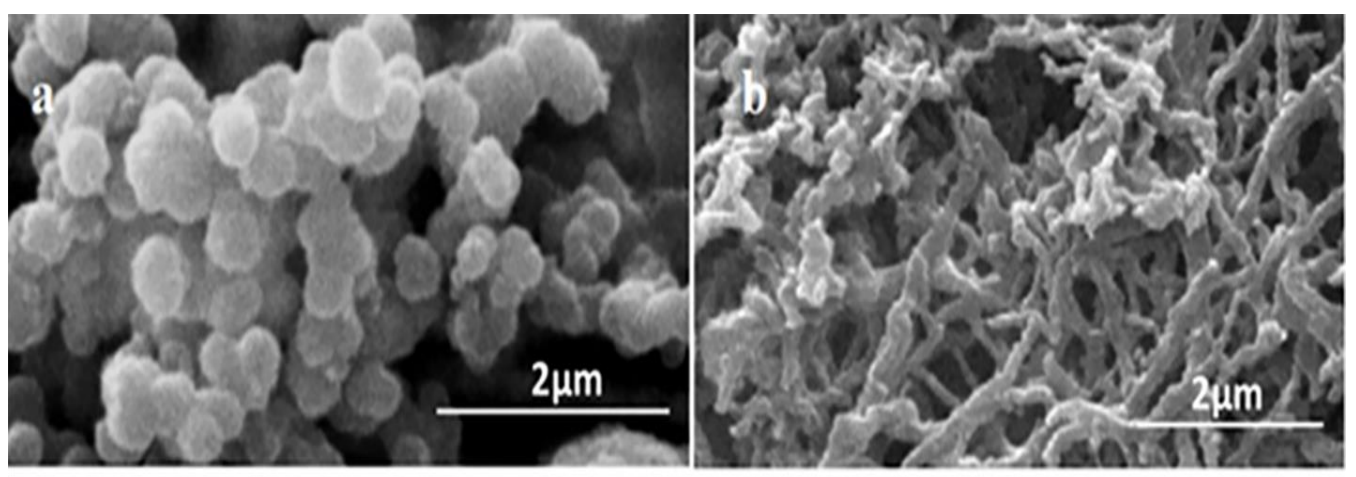

Figure 1. SEM images of modified electrodes: a) GNP-CNF/Chi-GEs) and b) CNF/Chi-GEs.

GNP-CNF/Chi-GEs: GNP: gold nanoparticle, CNF: carbon nanofiber, Chi: chitosan, GE: graphene electrode.

\subsection{Characterization of aptasensor by $C V$ and EIS.}

Electrochemical behaviors of electrodes; unmodified GE, CNF-Chi/GE, GNPs/CNFChi/GE, GNPs/CNF-Chi/GEs linked with the aptamer were conducted by cyclic voltammetry (CV) and electrochemical impedance spectroscopy (EIS).

The redox peaks of $[\mathrm{Fe}(\mathrm{CN}) 6]^{3-/ 4-}$ were recorded to demonstrate of immobilization/adsorption on the GE. In order to step by step, modifications of electrodes were investigated in $\left[\mathrm{Fe}(\mathrm{CN})_{6}\right]^{3-14-}(0.1 \mathrm{M})$ containing $\mathrm{KCl}(0.1 \mathrm{M})$ and $\mathrm{PBS}(0.1 \mathrm{M}, \mathrm{pH}=7.4)$ as a redox probe. Then EIS $(0.01 \mathrm{~Hz}-100 \mathrm{kHz})$ and $\mathrm{CV}(-0.2$ to $0.7 \mathrm{~V}$ with a scan rate of $0.1 \mathrm{~V} / \mathrm{s})$ measurements were done to verify each step of the GE modification.

Immobilization/adsorption of substances leads to the retardation of the electron transfer rate between the electrochemical double layer and redox probe and increases the charge transfer resistance for the redox probe to access the electrochemical double-layer [55].

The efficiency of the immobilization/adsorption of monolayer substances in blocking redox reactions is called the kinetics of the redox probe and is shown by peak-to-peak separation [56]. Nyquist plot and cyclic voltammograms of aptasensor were displayed in Figure 2. Fig 2a. depicts the EIS and CV curve of the bare GE. (Curve 2a: peak separation $179.5 \mathrm{mV}$, peak current $6 \mu \mathrm{A}$ and $\mathrm{R}_{\mathrm{ct}}=1540 \Omega$ ).

After modification with CNF, the peak current displayed a sharp increase. (Curve $2 \mathrm{~b}$ : peak current $(36 \mu \mathrm{A})$, peak separation $(167 \mathrm{mV})$, and $\left.\mathrm{R}_{\mathrm{ct}}=462 \Omega\right)$. This increase in the current could be attributed to the increase of the surface area on the active site of the electrode, which enhanced the electron transfer of $\left[\mathrm{Fe}(\mathrm{CN})_{6}\right]^{3-/ 4-}$ to the electrode surface.

In the next step, The GNPs were electrochemically deposited on the surface of CNFChi modified GE. For this aim, CNF-Chi modified GE was immersed in chloroauric acid solution. Electrochemical behaviors of the electrode were determined after modification with GNPs in curve c. (Curve 2c: peak current $(47 \mu \mathrm{A})$, peak separation $(158 \mathrm{mV})$, and $\left.\mathrm{R}_{\mathrm{ct}}=295 \Omega\right)$ ). Probably as a result of large surface area related to the incorporation of GNPs and the presence of $\mathrm{CNF}$, the effective increase in the electrical conductivity, and the current response of the electrode was observed. 
When the aptamer was fixed on the GNPs/CNF-Chi electrode, a noticeable decrease in peak current and an increase in separation peak was detected (Curve $2 \mathrm{~d}$ : peak current $(32 \mu \mathrm{A})$, separation peak $(169 \mathrm{mV}))$ ). These findings could have resulted in the electrostatic repulsion between the negatively charged aptamer sequence and anionic redox indicator $\left[\mathrm{Fe}(\mathrm{CN})_{6}\right]^{3-/ 4-}$ and consequently causes an increase in electron-transfer resistance [57]. These results demonstrated that CNF-Chi, GNPs, and Salmonella enterica aptamer sequences had been successfully fixed on the surface of GE.

Following the previous process, we decided to experiment with $\left[\mathrm{Fe}(\mathrm{CN})_{6}\right]^{3-14-}$ but since the Salmonella enterica in the ferric/ferrous solution underwent shock, we had to continue the process in methylene blue Solution (Figure 2e). In the final step, by adding Salmonella enterica, the electrode surface was saturated as a result of the reaction of Salmonella enterica with an aptamer-consequently, the current decreased (Figure 2f).
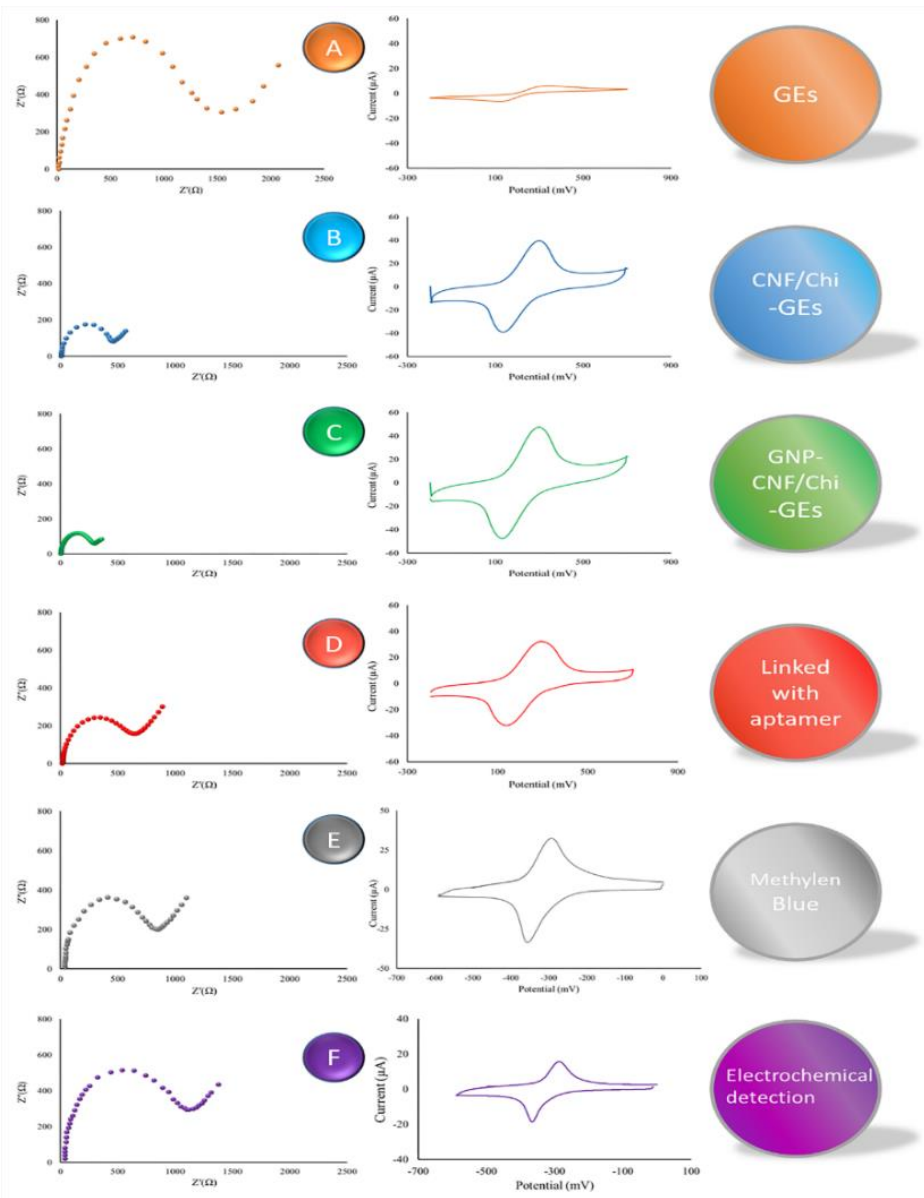

Figure 2. CV and EIS were utilized to study electrochemical behaviors of electrodes (recorded in PBS containing $0.1 \mathrm{M}\left[\mathrm{Fe}(\mathrm{CN})_{6}\right]^{3-14-}$ and $\mathrm{KCl} 0.1 \mathrm{M}$, PBS $\left.0.1 \mathrm{M}\right)$. Salmonella enterica concentration was $10^{3}$ $\mathrm{CFU} / \mathrm{mL}$.

3.3. Optimization of experimental conditions for electrochemical detection of Salmonella enterica.

To improve the sensitivity of aptasensor and achieve to low LOD, the main parameters involved in the performance of aptasensor (e.g., the sonication time, CNF volume, $p H$, and incubation time) were optimized.

To achieve a uniform mixture of carbon nanofiber in the DMF solution, a sonication bath was used, and the optimum time for sonication was investigated. A range of 10 to 40 
minutes was studied. The electrochemical behavior of the GE along with the carbon nanofiber mixture at different times in a $\left[\mathrm{Fe}(\mathrm{CN})_{6}\right]^{3-/ 4-}$ solution $(0.1 \mathrm{M})$ is shown in Figure $3 \mathrm{a}$, the increasing of the sonication time more than 20 minutes, leads to the breakage of the fibers into smaller pieces and their alteration from the fiber form, which reduces the current. Indeed, the surface-active sites (H-plane) and the surface area of the nanofibers are two factors affecting the amount of electron transfer; and the final current depends on the interaction between these two factors, which should be optimal.

Since the volume of the CNF is an important factor in aptasensor efficiency, optimization of its volume seems very important. Thus various volumes of CNF solution ( 1 to $4 \mu \mathrm{L}$ ) were tested, according to the result, $3 \mu \mathrm{L}$ of CNF on the surface of CNF/Chi-GEs was considered as the optimal volume (Figure $3 b$ ). The decrease in the current due to the increase in the volume of CNF can be attributed to the compression of nanofibers and hence reduction of surface area.

The electrochemical response of the aptasensor was examined at different $\mathrm{pH}$ values (from 6 to 9). The results showed that the current increased in an acidic $\mathrm{pH}$ range with a sharp peak at pH 7.4 and then decreased as pH moved to 9 (basic solution) (Figure 3c). The suggested mechanism of this behavior could be the adsorption of different ionic charges on the surface of the aptasensor at different $\mathrm{pH}$. In the basic solution, due to the presence of the negatively charged $\mathrm{OH}^{-}$ions on the $\mathrm{GE}$ surface, $\left[\mathrm{Fe}(\mathrm{CN})_{6}\right]^{3-/ 4-}$ as redox elements are repulsed, which resulted in the reduction of current. On the other hand, $\mathrm{H}^{+}$ions in the acidic $\mathrm{pH}$ cause inverse effects, and as a result, the current response increased. According to the described mechanism, the optimal $\mathrm{pH}$ would be 7.4 in which the least interactions happened, and the highest current response was obtained.

To obtain the optimal incubation time for the detection of Salmonella enterica, the modified GE was incubated with a $10^{3} \mathrm{CFU} / \mathrm{mL}$ bacteria, and subsequently, the curve of the current was measured at different incubation times. Figure $3 \mathrm{~d}$ shows the $\mathrm{CV}$ curve in terms of incubation time. It could be concluded that, with increasing incubation times from $10 \mathrm{~min}$ to $40 \mathrm{~min}$, the current decreases due to the robust interaction between the aptamer and Salmonella enterica. After $40 \mathrm{~min}$, the current was constant. Therefore, the incubation time of $40 \mathrm{~min}$ was considered an optimal time for further experiments.

\subsection{Electrochemical experiment to the detection of Salmonella enterica.}

Since the DPV technique is more sensitive than CV, the quantitative analyses of Salmonella enterica were performed by this technique [58]. Serial dilutions of Salmonella enterica in the range of 10 to $10^{5} \mathrm{CFU} / \mathrm{mL}$ were analyzed for electrochemical detection of Salmonella enterica using this technique. Aptasensor was incubated in the serial dilutions of Salmonella enterica in PBS buffer $(0.1 \mathrm{M}, \mathrm{pH}=7.4)$ and subsequently detected in PBS under the optimal experimental conditions. (Modulation time $=0.05 \mathrm{~s}$, interval time $=0.2 \mathrm{~s}$, potential range of -0.6 to $0.0 \mathrm{~V}$, modulation amplitude $=0.05 \mathrm{~V}$ ).

As it is shown in the inset of Figure 4, with increasing Salmonella enterica concentrations in the range of 10 to $10^{5} \mathrm{CFU} / \mathrm{mL}$, the electron transfers were disrupted between the redox electrode and electrolyte by the hindrance effect of aptamer-Salmonella enterica complex, which in result a higher resistance and a smaller current.

The calibration curve between the value of $\Delta \mathrm{I}(\mu \mathrm{A})$ and the concentration of Salmonella enterica $(\log (\mathrm{C}$ salmonella $)(\mathrm{Cfu} / \mathrm{ml}))$ is seen in Figure 4 . The result indicates that there is a linear relationship between the current value and the Salmonella enterica concentration with the 
regression equation of $\mathrm{I}(\mu \mathrm{A})=-18.675 \log ($ Csalmonella $)(\mathrm{Cfu} / \mathrm{mL})+2.4955$ and $\mathrm{R}^{2}=0.9982$. The calculated LOD was $1.223(\mathrm{Cfu} / \mathrm{mL})$ (defined as $\mathrm{S} / \mathrm{N}=3$ ) [59] and LOQ was 4.076 (CFU/mL).

The reproducibility is considered as a key factor in the development of aptasensor; to the evaluation of reproducibility, three equally assembled aptasensor was used for the detection of Salmonella enterica at $10^{3} \mathrm{CFU} / \mathrm{mL}$. The relative standard deviation value (RSD) of results was $3.7 \%$, which indicates this aptasensor has excellent reproducibility under the experimental conditions. To investigate the storage stability of fabricated aptasensors, three aptasensors were kept at $4{ }^{\circ} \mathrm{C}$ for two weeks without any preservatives. No significant change in the initial signal $94.92 \%$ was found in the frequent assays (every 3 days), indicating that no significant decomposition occurred in long term storage.
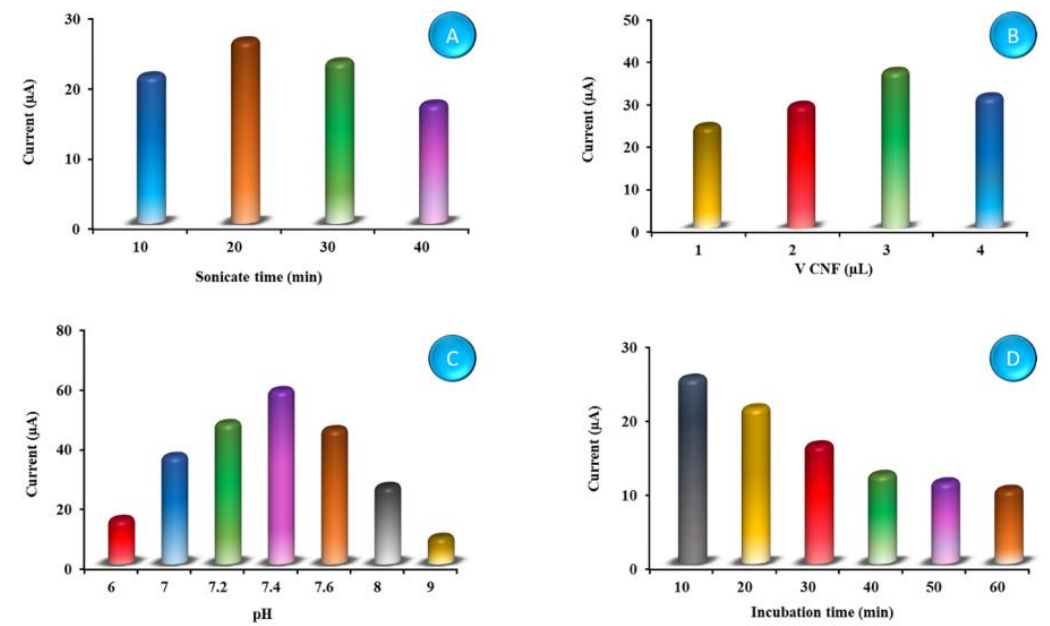

Figure 3. Effect of sonication time of CNF (A), the volume of CNF (B) $\mathrm{pH}(\mathrm{C})$, and an incubation time of Salmonella (D) on the current in $10^{3} \mathrm{CFU} / \mathrm{mL}$ of Salmonella enterica.

\subsection{Comparison of the Salmonella enterica aptasensor performance with PCR technique.}

Salmonella aptasensor was compared with the PCR technique at the same concentrations. As can be seen in Figure 5, PCR cannot detect Salmonella enterica in the concentrations less than $\left(10^{2} \mathrm{CFU} / \mathrm{mL}\right)$, whereas the proposed biosensor could detect it with lower concentrations such as $10 \mathrm{CFU} / \mathrm{mL}$.

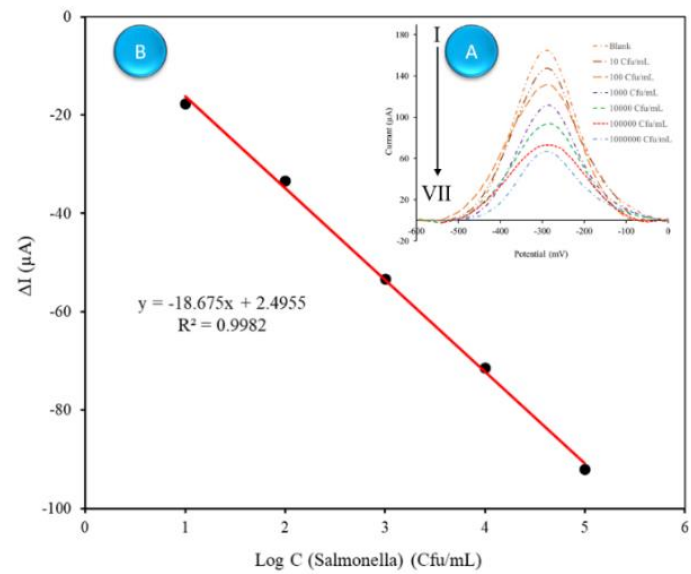

Figure 4. (a) DPV curves with different Salmonella enterica concentrations I) blank, II) $10 \mathrm{cfu} / \mathrm{mL}$, III) $10^{2}$ $\mathrm{Cfu} / \mathrm{mL}, \mathrm{IV}$ ) $\left.\left.10^{3} \mathrm{cfu} / \mathrm{mL}, \mathrm{V}\right) 10^{4} \mathrm{cfu} / \mathrm{mL}, \mathrm{VI}\right) 10^{5} \mathrm{cfu} / \mathrm{mL}$ and VII) $10^{6} \mathrm{cfu} / \mathrm{mL}$ in $0.1 \mathrm{M}$ PBS at $\mathrm{pH}$ 7.4. (b) Calibration curve of the electrochemical aptasensor for detection of Salmonella enterica. 


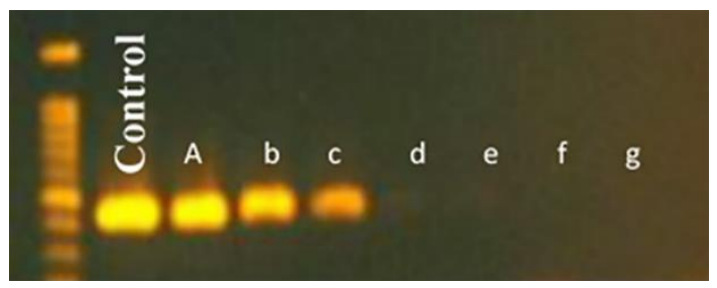

Figure 5. PCR result for Salmonella enterica with concentrations of (a) $10^{6} \mathrm{cfu} / \mathrm{mL}$ (b) $10^{5} \mathrm{cfu} / \mathrm{mL}$ (c) $10^{4}$ $\mathrm{cfu} / \mathrm{mL}$ (d) $10^{3} \mathrm{cfu} / \mathrm{mL}$ (e) $10^{2} \mathrm{cfu} / \mathrm{mL}$ (f) $10 \mathrm{cfu} / \mathrm{mL}$ (g) $1 \mathrm{cfu} / \mathrm{mL}$.

\subsection{Evaluation of the selectivity of the developed aptasensor.}

Selectivity is considered an important factor for the development of sensors, especially for real sample analysis. For the investigation of selectivity, the engineered GE was incubated with $10^{3} \mathrm{CFU} / \mathrm{mL}$ of each type of bacterium, including E.coli, P.aeruginosa, and S.aureus as control.

According to the DPV results, the signal current was very low, these results showed a negligible affinity for E.coli, P.aeruginosa, and S.aureus, whereas the high specificity was achieved for Salmonella enterica, as shown in Figure 6.

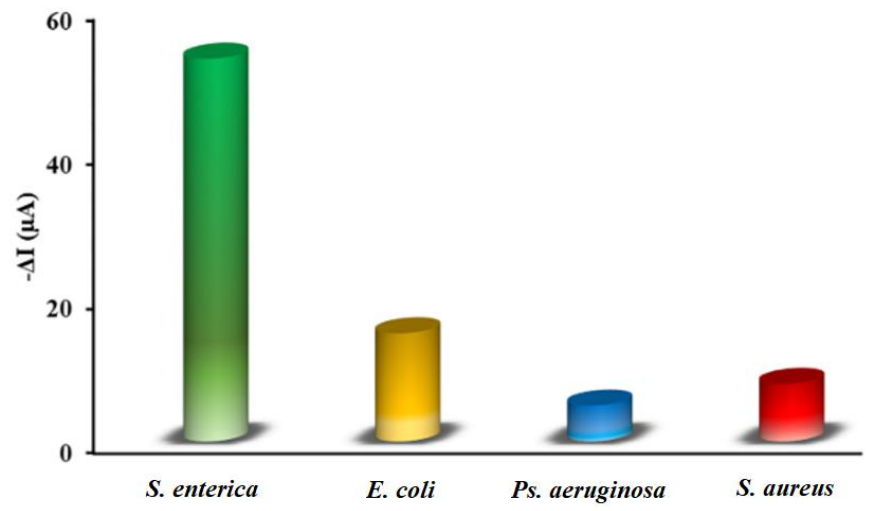

Figure 6. Sensor responses to $10^{3} \mathrm{CFU} / \mathrm{mL}$ (a) Salmonella enterica, (b) E. coli, (c) P.aeruginosa, and (d) S. aureus was conducted by DPV.

\subsection{Application of the aptasensor in the analysis of real samples.}

To determine the detection accuracy of the proposed aptasensor for real samples, different concentrations of Salmonella enterica $\left(10^{2}\right.$ to $\left.10^{4} \mathrm{CFU} / \mathrm{mL}\right)$ was spiked with full-fat milk. The processes of the sample preparation were briefly described as follows: the milk was diluted 1:1 with the BSAT buffer (PBST is PBS with 0.05\% Tween) then spiked with different Salmonella enterica concentrations[60]. As can be shown in Table 2, good and acceptable recoveries values for Salmonella enterica were acquired in the range between $96.5 \%$ and $106 \%$ (Table 2). These results reveal that the proposed aptasensor could be applied as a rapid, specific, and accurate approach to determine Salmonella enterica in full-fat milk.

Table 2. Recoveries study of Salmonella enterica in full-fat milk sample.

\begin{tabular}{c|c|c|c} 
Sample & $\begin{array}{c}\text { Added } \\
\text { Concentration } \\
(\mathbf{c f u} / \mathbf{m L})\end{array}$ & $\begin{array}{c}\text { Average value of Detected Concentration } \\
(\mathbf{c f u} / \mathbf{m L} \\
\mathbf{n = 1 0}\end{array}$ & $\begin{array}{c}\text { Recovery } \\
\text { Ratio } \\
(\mathbf{\%} \mathbf{n}=\mathbf{1 0})\end{array}$ \\
\hline No.1 & 100 & 106 & 106 \\
\hline No.2 & 1000 & 968 & 96.5 \\
\hline No.3 & 10000 & 9873 & 98.7
\end{tabular}


A brief comparison between our constructed aptasensor and previously published studies for the determination of Salmonella enterica was provided in Table 3. In comparison with the previously reported researches, the key feature of our aptasensor would be very low LOD for Salmonella enterica and linear regression in the wide range.

Table 3. Comparison of the engineered apasensor with previously reported studies for determination of

\begin{tabular}{l|l|l|l}
$\begin{array}{l}\text { Salmonella enterica. } \\
\text { Bosensor for detection } \\
\text { of Salmonella enterica }\end{array}$ & $\begin{array}{l}\text { Liner range } \\
\text { (CFU/mL) }\end{array}$ & $\begin{array}{l}\text { LOD } \\
\text { (CFU/mL) }\end{array}$ & Ref \\
\hline $\begin{array}{l}\text { Bacteriophages in } \\
\text { capacitive biosensors }\end{array}$ & 10 to $10^{5}$ & 10 & {$[61]$} \\
\hline $\begin{array}{l}\text { Spiny gold nanoparticles } \\
\text { in SERS aptasensor }\end{array}$ & 10 to $10^{5}$ & 4 & {$[62]$} \\
\hline $\begin{array}{l}\text { Nanoporous gold in } \\
\text { electrochemical aptasensor }\end{array}$ & $6.5 \times 10^{2}$ to $6.5 \times 10^{8}$ & 1 & {$[8]$} \\
\hline MB- GNPs/CNF-Chi/GE aptasensor & 10 to $10^{5}$ & 1.223 & This work
\end{tabular}

\section{Conclusions}

Salmonella enterica is considered as one of the most frequently available foodborne pathogenic bacteria in contaminated foods. In this study, we have developed a novel competitive voltammetric aptasensor based on GNPs/CNF-Chi/GEs linked with the aptamer for the detection of Salmonella enterica Serovar.

According to results, after modification with CNF and GNPs, the peak current displayed a sharp increase. This increase in the current could be related to the increase of the surface area on the active site of the electrode, which enhanced the electron transfer to the electrode surface.

Due to the critical features of the aptamer such as selectivity and specificity, the designed aptasensor exhibited good linear relationships in the wide range of 10 to $10^{5}$ $(\mathrm{CFU} / \mathrm{mL})$ with a detection limit of $1.223(\mathrm{CFU} / \mathrm{mL})$ for Salmonella enterica which was even better than PCR technique.

Furthermore, in the application of the aptasensor in the real sample, excellent performance without any significant interfering effect with other components was confirmed.

Therefore, the present study demonstrated that the constructed aptasensor could be suggested as a simple, rapid approach for highly specific, sensitive, and accurate detection of Salmonella enterica. This aptasensor has a high potential to be used to detect Salmonella enterica in food products.

\section{Funding}

This research was funded by Tehran University of Medical Sciences (TUMS) under grant No. 95-04-87-33406.

\section{Acknowledgments}

This research has no acknowledgment.

\section{Conflicts of Interest}

The authors declare no conflict of interest. 


\section{References}

1. Liu, Y.; Du, S.; Horikawa, S.; Chen, I.H.; Chai, Y.; Wikle, H.C.; Suh, S.J.; Chin, B.A. Application of 2Dimensional Coil Detector for the Sensitive Direct Salmonella Detection on Plastic Board. ECS Transactions 2017, 77, 1799-1807, https://doi.org/10.1149/07711.1799ecst.

2. Klemm, E.J.; Shakoor, S.; Page, A.J.; Qamar, F.N.; Judge, K.; Saeed, D.K.; Wong, V.K.; Dallman, T.J.; Nair, S.; Baker, S. Emergence of an extensively drug-resistant Salmonella enterica serovar Typhi clone harboring a promiscuous plasmid encoding resistance to fluoroquinolones and third-generation cephalosporins. MBio 2018, 9, e00105-00118, https://doi.org/10.1128/mbio.00105-18.

3. Nair, V.T.D.; Venkitanarayanan, K.; Kollanoor Johny, A. Antibiotic-resistant Salmonella in the food supply and the potential role of antibiotic alternatives for control. Foods 2018, 7, https://dx.doi.org/10.3390\%2Ffoods7100167.

4. Swaminathan, B.; Feng, P. Rapid detection of foodborne pathogenic bacteria. Annual review of microbiology 1994, 48, 401-426, https://doi.org/10.1146/annurev.mi.48.100194.002153.

5. Gehring, A.G.; Crawford, C.G.; Mazenko, R.S.; Van Houten, L.J.; Brewster, J.D. Enzyme-linked immunomagnetic electrochemical detection of Salmonella typhimurium. Journal of immunological methods 1996, 195, 15-25, https://doi.org/10.1016/0022-1759(96)00076-2.

6. Miller, N.D.; Davidson, P.; D’Souza, D.H. Real-time reverse-transcriptase PCR for Salmonella Typhimurium detection from lettuce and tomatoes. LWT-Food Science and Technology 2011, 44, 10881097, https://doi.org/10.1016/j.lwt.2010.08.003.

7. Yang, L.; Bashir, R. Electrical/electrochemical impedance for rapid detection of foodborne pathogenic bacteria. Biotechnology advances 2008, 26, 135-150, https://doi.org/10.1016/j.biotechadv.2007.10.003.

8. Ranjbar, S.; Shahrokhian, S.; Nurmohammadi, F. Nanoporous gold as a suitable substrate for preparation of a new sensitive electrochemical aptasensor for detection of Salmonella typhimurium. Sensors and Actuators B: Chemical 2018, 255, 1536-1544, https://doi.org/10.1016/j.snb.2017.08.160.

9. Erdem, A. Nanomaterial-based electrochemical DNA sensing strategies. Talanta 2007, 74, 318-325, https://doi.org/10.1016/j.talanta.2007.10.012.

10. Coté, G.L.; Lec, R.M.; Pishko, M.V. Emerging biomedical sensing technologies and their applications. IEEE Sensors Journal 2003, 3, 251-266.

11. Hassani, S.; Akmal, M.R.; Salek-Maghsoudi, A.; Rahmani, S.; Ganjali, M.R.; Norouzi, P.; Abdollahi, M. Novel label-free electrochemical aptasensor for determination of Diazinon using gold nanoparticlesmodified screen-printed gold electrode. Biosensors and Bioelectronics 2018, 120, 122-128, https://doi.org/10.1016/j.bios.2018.08.041.

12. Salek-Maghsoudi, A.; Vakhshiteh, F.; Torabi, R.; Hassani, S.; Ganjali, M.R.; Norouzi, P.; Hosseini, M.; Abdollahi, M. Recent advances in biosensor technology in assessment of early diabetes biomarkers. Biosensors and Bioelectronics 2018, 99, 122-135, https://doi.org/10.1016/j.bios.2017.07.047.

13. Hassani, S.; Momtaz, S.; Vakhshiteh, F.; Maghsoudi, A.S.; Ganjali, M.R.; Norouzi, P.; Abdollahi, M. Biosensors and their applications in detection of organophosphorus pesticides in the environment. Archives of toxicology 2017, 91, 109-130, https://doi.org/10.1007/s00204-016-1875-8.

14. Zhang, Y.; Figueroa-Miranda, G.; Lyu, Z.; Zafiu, C.; Willbold, D.; Offenhäusser, A.; Mayer, D. Monitoring amyloid- $\beta$ proteins aggregation based on label-free aptasensor. Sensors and Actuators B: Chemical 2019, 288, 535-542, https://doi.org/10.1016/j.snb.2019.03.049.

15. Derikvand, H.; Roushani, M.; Abbasi, A.R.; Derikvand, Z.; Azadbakht, A. Design of folding-based impedimetric aptasensor for determination of the nonsteroidal anti-inflammatory drug. Analytical biochemistry 2016, 513, 77-86, https://doi.org/10.1016/j.ab.2016.06.013.

16. Kukushkin, V.I.; Ivanov, N.M.; Novoseltseva, A.A.; Gambaryan, A.S.; Yaminsky, I.V.; Kopylov, A.M.; Zavyalova, E.G. Highly sensitive detection of influenza virus with SERS aptasensor. PloS one 2019, 14, https://dx.doi.org/10.1371\%2Fjournal.pone.0216247.

17. Feng, L.; Chen, Y.; Ren, J.; Qu, X. A graphene functionalized electrochemical aptasensor for selective label-free detection of cancer cells. Biomaterials 2011, 32, 2930-2937, https://doi.org/10.1016/j.biomaterials.2011.01.002.

18. Blidar, A.; Feier, B.; Tertis, M.; Galatus, R.; Cristea, C. Electrochemical surface plasmon resonance (ECSPR) aptasensor for ampicillin detection. Analytical and bioanalytical chemistry 2019, 411, 1053-1065, https://doi.org/10.1007/s00216-018-1533-5.

19. Joshi, R.; Janagama, H.; Dwivedi, H.P.; Kumar, T.S.; Jaykus, L.A.; Schefers, J.; Sreevatsan, S. Selection, characterization, and application of DNA aptamers for the capture and detection of Salmonella enterica serovars. Molecular and cellular probes 2009, 23, 20-28, https://doi.org/10.1016/j.mcp.2008.10.006.

20. Ma, X.; Jiang, Y.; Jia, F.; Yu, Y.; Chen, J.; Wang, Z. An aptamer-based electrochemical biosensor for the detection of Salmonella. Journal of microbiological methods 2014, 98, 94-98, https://doi.org/10.1016/j.mimet.2014.01.003.

21. Alamdari, N.H.; Alaei-Beirami, M.; Shandiz, S.A.S.; Hejazinia, H.; Rasouli, R.; Saffari, M.; Ebrahimi, S.E.S.; Assadi, A.; Ardestani, M.S. Gd3+-asparagine-anionic linear globular dendrimer second- 
generation G2 complexes: novel nanobiohybrid theranostics. Contrast media \& molecular imaging 2017, 2017, https://doi.org/10.1155/2017/3625729.

22. Rasouli, R.; Barhoum, A.; Uludag, H. A review of nanostructured surfaces and materials for dental implants: surface coating, patterning and functionalization for improved performance. Biomaterials science 2018, 6, 1312-1338, https://doi.org/10.1039/c8bm00021b.

23. Chen, T.; Sheng, A.; Hu, Y.; Mao, D.; Ning, L.; Zhang, J. Modularization of three-dimensional gold nanoparticles/ferrocene/liposome cluster for electrochemical biosensor. Biosensors and Bioelectronics 2019, 124, 115-121, https://doi.org/10.1016/j.bios.2018.09.101.

24. Niu, Y.; Xie, H.; Luo, G.; Weng, W.; Ruan, C.; Li, G.; Sun, W. Electrochemical performance of myoglobin based on $\mathrm{TiO}$ 2-doped carbon nanofiber decorated electrode and its applications in biosensing. RSC Advances 2019, 9, 4480-4487, https://doi.org/10.1039/C8RA07910B.

25. Radhakrishnan, S.; Mathiyarasu, J. Graphene-Carbon Nanotubes Modified Electrochemical Sensors. In: Graphene-Based Electrochemical Sensors for Biomolecules. Elsevier: 2019; pp. 187-205, https://doi.org/10.1016/B978-0-12-815394-9.00008-X.

26. Krishnan, S.K.; Singh, E.; Singh, P.; Meyyappan, M.; Nalwa, H.S. A review on graphene-based nanocomposites for electrochemical and fluorescent biosensors. RSC Advances 2019, 9, 8778-8881, https://doi.org/10.1039/C8RA09577A.

27. Zhang, J.; Han, D.; Yang, R.; Ji, Y.; Liu, J.; Yu, X. Electrochemical detection of DNA hybridization based on three-dimensional $\mathrm{ZnO}$ nanowires/graphite hybrid microfiber structure. Bioelectrochemistry 2019, 128, 126-132, https://doi.org/10.1016/j.bioelechem.2019.04.003.

28. Campuzano, S.; Yáñez-Sedeño, P.; Pingarrón, J.M. Carbon Dots and Graphene Quantum Dots in Electrochemical Biosensing. Nanomaterials 2019, 9, https://doi.org/10.3390/nano9040634.

29. Ribovski, L.; dos Santos, F.A.; Zucolotto, V.; Janegitz, B.C. Gold nanorods and poly (amido amine) dendrimer thin film for biosensing. Journal of Solid State Electrochemistry 2019, 1-11, https://doi.org/10.1007/s10008-019-04247-z.

30. Shakoori, Z.; Salimian, S.; Kharrazi, S.; Adabi, M.; Saber, R. Electrochemical DNA biosensor based on gold nanorods for detecting hepatitis B virus. Analytical and bioanalytical chemistry 2015, 407, 455461, https://doi.org/10.1007/s00216-014-8303-9.

31. Meyyappan, M.; Sunkara, M.K. Inorganic nanowires: applications, properties, and characterization. CRC Press: 2009.

32. Lee, M.H.; Wang, S.Y.; Chiang, W.H.; Feng, H.; Huang, T.Y.; Yeh, M.H.; Wu, K.C.W.; Ho, K.C. Platinum nanoparticles decorated graphene nanoribbon with eco-friendly unzipping process for electrochemical sensors. Journal of the Taiwan Institute of Chemical Engineers 2019, 96, 566-574, https://doi.org/10.1016/j.jtice.2018.11.012.

33. Meng, F.; Sun, H.; Huang, Y.; Tang, Y.; Chen, Q.; Miao, P. Peptide cleavage-based electrochemical biosensor coupling graphene oxide and silver nanoparticles. Analytica chimica acta 2019, 1047, 45-51, https://doi.org/10.1016/j.aca.2018.09.053.

34. Yasun, E.; Gulbakan, B.; Ocsoy, I.; Yuan, Q.; Shukoor, M.I.; Li, C.; Tan, W. Enrichment and detection of rare proteins with aptamer-conjugated gold nanorods. Analytical chemistry 2012, 84, 6008-6015, https://doi.org/10.1021/ac300806s.

35. Zhang, Y.; Liu, Y.; He, J.; Pang, P.; Gao, Y.; Hu, Q. Electrochemical behavior of graphene/Nafion/Azure I/Au nanoparticles composites modified glass carbon electrode and its application as nonenzymatic hydrogen peroxide sensor. Electrochimica Acta 2013, 90, 550-555, https://doi.org/10.1016/j.electacta.2012.12.068.

36. Rasouli, R.; Barhoum, A. Advances in nanofibers for antimicrobial drug delivery. In: Handbook of Nanofibers 2018; pp. 1-42, https://doi.org/10.1007/978-3-319-53655-2_33.

37. Rasouli, R.; Barhoum, A.; Bechelany, M.; Dufresne, A. Nanofibers for biomedical and healthcare applications. Macromolecular bioscience 2019, 19, https://doi.org/10.1002/mabi.201800256.

38. Barhoum, A.; Rasouli, R.; Yousefzadeh, M.; Rahier, H.; Bechelany, M. Nanofiber Technology: History and Developments. In: Handbook of Nanofibers 2018; 1-42.

39. Adabi, M.; Saber, R.; Naghibzadeh, M.; Faridbod, F.; Faridi-Majidi, R. Parameters affecting carbon nanofiber electrodes for measurement of cathodic current in electrochemical sensors: an investigation using artificial neural network. RSC Advances 2015, 5, 81243-81252, https://doi.org/10.1039/C5RA15541J.

40. Samadian, H.; Zakariaee, S.S.; Adabi, M.; Mobasheri, H.; Azami, M.; Faridi-Majidi, R. Effective parameters on conductivity of mineralized carbon nanofibers: an investigation using artificial neural networks. RSC Advances 2016, 6, 111908-111918, https://doi.org/10.1039/C6RA21596C.

41. Naghibzadeh, M.; Firoozi, S.; Nodoushan, F.S.; Adabi, M.; Khoradmehr, A.; Fesahat, F.; Esnaashari, S.S.; Khosravani, M.; Tavakol, S.; Pazoki-Toroudi, H. Application of electrospun gelatin nanofibers in tissue engineering. Biointerface Research in Applied Chemistry 2018, 8, 3048-3052.

42. Esnaashari, S.S.; Naghibzadeh, M.; Adabi, M.; Faridi Majidi, R. Evaluation of the Effective Electrospinning Parameters Controlling Kefiran Nanofibers Diameter Using Modelling Artificial Neural 


Networks. Nanomedicine Research Journal 2017, 2, 249-24,
https://dx.doi.org/10.22034/nmrj.2017.04.005.

43. Samadian, H.; Mobasheri, H.; Hasanpour, S.; Faridi Majidi, R. Electrospinning of polyacrylonitrile nanofibers and simulation of electric field via finite element method. Nanomedicine Research Journal 2017, 2, 87-92, https://dx.doi.org/10.22034/nmrj.2017.57231.1060.

44. Boroumand, S.; Hosseini, S.; Salehi, M.; Faridi Majidi, R. Drug-loaded electrospun nanofibrous sheets as barriers against postsurgical adhesions in mice model. Nanomedicine Research Journal 2017, 2, 6472, https://dx.doi.org/10.22034/nmrj.2017.23780.

45. Tang, X.; Liu, Y.; Hou, H.; You, T. Electrochemical determination of L-Tryptophan, L-Tyrosine and LCysteine using electrospun carbon nanofibers modified electrode. Talanta 2010, 80, 2182-2186, https://doi.org/10.1016/j.talanta.2009.11.027.

46. Adabi, M.; Saber, R.; Faridi-Majidi, R.; Faridbod, F. Performance of electrodes synthesized with polyacrylonitrile-based carbon nanofibers for application in electrochemical sensors and biosensors. Materials Science and Engineering: C 2015, 48, 673-678, https://doi.org/10.1016/j.msec.2014.12.051.

47. Eksin, E.; Erdem, A. Chitosan-carbon Nanofiber Modified Single-use Graphite Electrodes Developed for Electrochemical Detection of DNA Hybridization Related to Hepatitis B Virus. Electroanalysis 2016, https://doi.org/10.1002/elan.201501113.

48. Suginta, W.; Khunkaewla, P.; Schulte, A. Electrochemical biosensor applications of polysaccharides chitin and chitosan. Chemical Reviews 2013, 113, 5458-5479, https://doi.org/10.1021/cr300325r.

49. Yu, Z.; Luan, Y.; Li, H.; Wang, W.; Wang, X.; Zhang, Q. A disposable electrochemical aptasensor using single-stranded DNA-methylene blue complex as signal-amplification platform for sensitive sensing of bisphenol A. Sensors and Actuators B: Chemical 2019, 284, 73-80, https://doi.org/10.1016/j.snb.2018.12.126.

50. Wong, H.L.; Chattopadhyay, N.; Wu, X.Y.; Bendayan, R. Nanotechnology applications for improved delivery of antiretroviral drugs to the brain. Advanced drug delivery reviews 2010, 62, 503-517, https://doi.org/10.1016/j.addr.2009.11.020.

51. Ju, H.; Zhou, J.; Cai, C.; Chen, H. The electrochemical behavior of methylene blue at a microcylinder carbon fiber electrode. Electroanalysis 1995, 7, 1165-1170, https://doi.org/10.1002/elan.1140071213.

52. Jin, Y.; Yao, X.; Liu, Q.; Li, J. Hairpin DNA probe based electrochemical biosensor using methylene blue as hybridization indicator. Biosens Bioelectron 2007, 22, 1126-1130, https://doi.org/10.1016/j.bios.2006.04.011.

53. Fardsanei, F.; Dallal, M.M.S.; Douraghi, M.; Salehi, T.Z.; Mahmoodi, M.; Memariani, H.; Nikkhahi, F. Genetic diversity and virulence genes of Salmonella enterica subspecies enterica serotype Enteritidis isolated from meats and eggs. Microbial pathogenesis 2017, 107, 451-456, https://doi.org/10.1016/j.micpath.2017.04.026.

54. Mirzaie, S.; Hassanzadeh, M.; Ashrafi, I. Identification and characterization of Salmonella isolates from captured house sparrows. Turkish Journal of Veterinary and Animal Sciences 2010, 34, 181-186, https://doi.org/10.3906/vet-0810-43.

55. Gupta, A.K.; Mitra, C.K. Simple and sensitive electrochemical impedimetric approach towards analysis of biophysical interaction. Biochemical and biophysical research communications 2015, 465, 471-475, https://doi.org/10.1016/j.bbrc.2015.08.041.

56. Shamsipur, M.; Asgari, M.; Maragheh, M.G.; Matt, D. Impedimetric sensing of cesium ion based on a thiacalix [4] arene self-assembled gold electrode. Sensors and Actuators B: Chemical 2015, 209, 9-14, https://doi.org/10.1016/j.snb.2014.11.047.

57. Kashefi-Kheyrabadi, L.; Mehrgardi, M.A.; Wiechec, E.; Turner, A.P.; Tiwari, A. Ultrasensitive detection of human liver hepatocellular carcinoma cells using a label-free aptasensor. Analytical chemistry 2014, 86, 4956-4960, https://doi.org/10.1021/ac500375p.

58. Yang, F.; Wang, P.; Wang, R.; Zhou, Y.; Su, X.; He, Y.; Shi, L.; Yao, D. Label free electrochemical aptasensor for ultrasensitive detection of ractopamine. Biosensors and Bioelectronics 2016, 77, 347-352, https://doi.org/10.1016/j.bios.2015.09.050.

59. Swartz, M.E.; Krull, I.S. Handbook of analytical validation. CRC Press: 2012.

60. Conzuelo, F.; Gamella, M.; Campuzano, S.; Pinacho, D.G.; Reviejo, A.J.; Marco, M.P.; Pingarrón, J.M. Disposable and integrated amperometric immunosensor for direct determination of sulfonamide antibiotics in milk. Biosensors and Bioelectronics 2012, 36, 81-88, https://doi.org/10.1016/j.bios.2012.03.044.

61. Ertürk, G.; Lood, R. Bacteriophages as biorecognition elements in capacitive biosensors: Phage and host bacteria detection. Sensors and Actuators B: Chemical 2018, 258, 535-543, https://doi.org/10.1016/j.snb.2017.11.117.

62. Ma, X.; Xu, X.; Xia, Y.; Wang, Z. SERS aptasensor for Salmonella typhimurium detection based on spiny gold nanoparticles. Food Control 2018, 84, 232-237, https://doi.org/10.1016/j.foodcont.2017.07.016. 